\title{
Marlo Johnston, Guy de Maupassant
}

\section{Ida Merello}

\section{(2) OpenEdition}

\section{Journals}

\section{Edizione digitale}

URL: http://journals.openedition.org/studifrancesi/3815

DOI: $10.4000 /$ studifrancesi.3815

ISSN: 2421-5856

\section{Editore}

Rosenberg \& Sellier

\section{Edizione cartacea}

Data di pubblicazione: 1 décembre 2012

Paginazione: 597

ISSN: 0039-2944

\section{Notizia bibliografica digitale}

Ida Merello, «Marlo Johnston, Guy de Maupassant», Studi Francesi [Online], 168 (LVI | III) | 2012, online dal 30 novembre 2015, consultato il 07 mars 2021. URL: http://journals.openedition.org/studifrancesi/ 3815 ; DOI: https://doi.org/10.4000/studifrancesi.3815

Questo documento è stato generato automaticamente il 7 mars 2021.

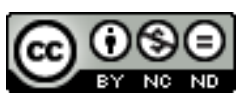

Studi Francesi è distribuita con Licenza Creative Commons Attribuzione - Non commerciale - Non opere derivate 4.0 Internazionale. 


\title{
Marlo Johnston, Guy de Maupassant
}

\author{
Ida Merello
}

\section{NOTIZIA}

MARLO JOHNSTON, Guy de Maupassant, Paris, Fayard 2012, pp. 1336.

1 L'opera si inserisce nella nobile tradizione inglese delle biografie d'autore, caratterizzandosi subito per l'immensità della mole, e in seconda battuta perché integralmente dovuta alla passione di una ricercatrice indipendente, che ha dedicato più di quindici anni alla raccolta dei documenti. Naturalmente la personalità anche biografica di Maupassant, con i misteri delle sue ammiratrici e della sua malattia era già stata oggetto di curiosità e attenzione, come testimonia l'ampia bibliografia offerta da Antonia Fonyi sul sito della «Société des études romantiques»; mentre nel 2003 anche Nadine Satiat, specialista di biografie (l'ultima su Gertrude Stein) ne aveva pubblicato una per Flammarion; l'A. intraprende però una sua personale ricerca, curvandosi nuovamente in prima persona sui materiali, e recuperandone moltissimi, riverificando così i fatti attraverso le interazioni dei punti di vista, e ripercorrendo la vita dello scrittore quasi giorno per giorno, facendo interagire insieme per ciascun elemento della biografia numerosi riferimenti, dalle lettere alla corrispondenza ai diari alle dichiarazioni agli articoli apparsi sui giornali, in un gioco di collegamenti vertiginoso. Procedendo addirittura dagli antenati settecenteschi della famiglia, l'A. scandisce poi la vita di Maupassant in sei parti, che, a partire dal momento dell'affermazione letteraria, ossia dal 1880, raggruppano periodi di tre anni, con un'analisi perciò davvero al rallentatore. Seguono tre annessi, che affrontano la questione dell'esistenza o meno di tre figli dello scrittore, la discussione scientifica sulla sifilide che ne provocò la morte $\mathrm{e}$ alcune osservazioni mediche sulla visione autoscopica. Nella prima parte sono messi molto bene in evidenza i legami di amicizia che legavano le famiglie Flaubert, Maupassant e Le Poittevin: l'A. dedica attenzione al personaggio di Alfred Le Poittevin, scagionato dall'accusa di follia, al rapporto affettivo di Gustave con Guy, che viene esaminato nelle pieghe più intime, ai legami di Guy con Turgenev. Ma una caratteristica dell'opera è quella di non operare una selezione dei fatti, bensì di riportare tutto quello 
che è riportabile, organizzandolo attraverso la successione cronologica. Così i rapporti erotici godono dello stesso spazio dei legami culturali, e le avventure con le amanti sconosciute hanno altrettanto rilievo della recezione delle opere letterarie. L'A. ci costringe insomma a tuffarci integralmente nella vita di Maupassant, offrendo un'enorme quantità di informazioni agli studiosi dell'opera, che potranno trovare nel suo lavoro conferma o scoperta di elementi di congiunzione tra la produzione letteraria e il particolare momento biografico, con spunti per riflessioni future. Già occasione di dibattito la diversità di opinione circa la paternità maupassantiana della pièce di Mme Thomassin, che non è universalmente riconosciuta. 